July 2011

\title{
Collection Development of HIV/AIDS Information Resources in American Libraries
}

Joseph G. Andrews Jr

San Jose State University, magdax27@gmail.com

Follow this and additional works at: https://scholarworks.sjsu.edu/ischoolsrj

Part of the Library and Information Science Commons

\section{Recommended Citation}

Andrews, J. G. (2011). Collection Development of HIV/AIDS Information Resources in American Libraries. School of Information Student Research Journal, 1(1). https://doi.org/10.31979/2575-2499.010105 Retrieved from https://scholarworks.sjsu.edu/ischoolsrj/vol1/iss1/5

This article is brought to you by the open access Journals at SJSU ScholarWorks. It has been accepted for inclusion in School of Information Student Research Journal by an authorized administrator of SJSU ScholarWorks. For more information, please contact scholarworks@sjsu.edu. 
Andrews: Collection Development of HIV/AIDS Resources

\title{
Collection Development of HIV/AIDS Information Resources in American Libraries
}

Human immunodeficiency virus (HIV)/acquired immunodeficiency syndrome (AIDS) remains an incurable epidemic that in the United States disproportionately affects men who have sex with men (MSM) and African Americans (Centers for Disease Control and Prevention [CDC], 2010b). Library and information science (LIS) professionals can play a vital role in keeping these higher risk groups informed about preventing or living with HIV/AIDS through a variety of current information resource formats that address their specific questions. This paper reviews collection development policies proposed by LIS professionals and libraries since the late 1980s and evaluates how these policies have taken higherrisk user groups into consideration. The review findings suggest that collection development policies have previously drawn attention to individual user groups and currently to user groups in developing countries, but that LIS researchers have consistently overlooked the most vulnerable groups of MSM and African Americans who still need up-to-date materials about the disease.

For statistics about HIV/AIDS in the United States the most recent publications available on the Centers for Disease Control and Prevention (CDC) website were consulted. For information about library policies that pertain to disabilities and HIV/AIDS as a disability, documents available on the CDC and the American Library Association (ALA) websites were referenced. Print and electronic materials that address HIV/AIDS-related collection development in American libraries proved more difficult to research as relatively few texts are written on the subject. Searches of LIS and scholarly databases, including Academic Search Premier, Emerald Management Xtra, Library Literature \& Information Science Full Text, Google Scholar, and ABI/INFORM Complete, as well as general search engines, retrieved materials and citations focused more on HIV/AIDS in developing African and Asian countries than in the United States. Consequently, bibliographic references in works that did address HIV/AIDSrelated collection development in American libraries were reviewed in a chainlike fashion, subsequently supporting the chronological trends described in this paper and making evident the lack of current HIV/AIDS resources tailored to MSM and African Americans.

\begin{abstract}
About HIV/AIDS
As a preface to the discussion of collection development policies related to HIV/AIDS, a background of the disease will underscore its severity in the United States and articulate its status as a disability relative to libraries. HIV cripples a person's immune system by destroying the CD4+ T cells that help fight diseases
\end{abstract}




\section{SLIS Student Research Journal}

July 2011, Volume 1, Issue 1

(CDC, 2010a). An HIV-positive person can develop AIDS, as the final stage of HIV infection, characterized by the immune system's inability to combat diseases and cancers. Although persons infected with HIV can delay the development of AIDS for decades by taking antiretroviral medications, no cure exists for the virus (CDC, 2010a). Scientific research has shown several possible routes of HIV infection; however, the three primary ways include unprotected sex with an HIVpositive person, sharing intravenous drug paraphernalia with an HIV-positive person, or being born to an HIV-positive mother (CDC, 2010a).

As of 2007 the CDC (2010b) estimates that 580,371 persons diagnosed with HIV live in the 37 states it studied, and that 459,594 persons with an AIDS diagnosis live in the United States. According to the CDC's 2008 estimates, the rate of HIV diagnoses in the 37 states from which it collected data was 19.4 per 100,000 population, while the rate of AIDS diagnoses in the United States was 12.2 per 100,000 population. From 2005 through 2008, the CDC (2010b) found no change in the rate of HIV diagnoses, except among people of Native American, Asian, and African descent, demonstrating the stark reality that HIV infections strike ethnic and racial minorities at a disproportionately higher rate than Caucasians in the United States.

The 2008 HIV infection rate for African Americans is 73.7 per 100,000 population, which is over three times higher than the overall rate of all other groups (CDC, 2010b). The 2008 CDC reported rates for Latino and Pacific Islander populations are also higher, at 25.0 and 22.8 per 100,000 population respectively. Another minority disproportionately affected by HIV includes men who have sex with men (MSM). From 2005 through 2008 the rate of HIV diagnoses among this group increased to 54\% of all HIV diagnoses in the 37 states studied in 2008, almost double the rate among people who contracted HIV through heterosexual contact (CDC, 2010b). Clearly, MSM and African Americans represent two higher-risk groups, not entirely mutually exclusive, of persons more prone to becoming infected with HIV.

\section{HIV/AIDS as a Disability}

Under the Americans with Disabilities Act (ADA) of 1990, HIV/AIDS is recognized as a disability, and a person diagnosed with HIV/AIDS, perceived to have an HIV/AIDS diagnosis, or associated with anyone who falls within these categories is protected from discrimination in "public accommodations, employment, transportation, state and local government services, and telecommunications" (ADA, 1996, p. 1). The ADA (2011) recognizes libraries as a public accommodation (Sec. 12281, 7(H)) wherein "no individual shall be discriminated against on the basis of disability in the full and equal enjoyment of the goods, services, facilities, privileges, advantages, or accommodations" (Sec. 


\section{Andrews: Collection Development of HIV/AIDS Resources}

12182, A). Depending on their funding sources, libraries would fall under state and local government services to also be considered places of employment.

The ALA's "Services to People with Disabilities: An Interpretation of the Library Bill of Rights" asserts that libraries should proactively provide equal access to its resources for all library users, including people with disabilities (ALA, 2009). Further bolstering the ADA, the ALA (1988) was early to adopt a resolution that recognized people with HIV/AIDS as handicapped individuals protected by anti-discrimination laws. With libraries' long-standing protection of people with AIDS/HIV in mind, this paper explores how libraries and LIS professionals in the United States have addressed HIV/AIDS issues through collection development, and whether their actions have taken into account the disproportionate effect that HIV/AIDS has on minority communities such as MSM and African Americans.

\section{Beginnings of HIV/AIDS Collection Development}

By 1989 the proliferation of scientific literature on AIDS garnered the attention of Self, Filardo, and Lancaster (1989), who concluded in their bibliometric survey of online databases that AIDS-related literature would continue to increase, and thus called "for the establishment of a specialized information center to collect this literature comprehensively to provide bibliographic control, and to exploit the literature in support of future research efforts" (p. 59); they noted their findings were in accordance with the CDC's intent to create a National AIDS Information Clearing System to serve as such an information center (CDC, 1990). This survey represented one of the first scholarly works within the LIS community to acknowledge the value of AIDS-related collection development; however, it could have expanded into the other subjects apparent in AIDS-related scientific literature, such as the prevalance of AIDS among MSM and African Americans. Referring to these realities would not have undermined the stance of Self et al. (1989) on an agency that collects comprehensive HIV/AIDS resources and could have spotlighted two higher risk segments of the general public, and by turn, library users with significant need for information about the developments in the HIV/AIDS epidemic.

During this period the CDC developed an information service known as the National AIDS Information Clearinghouse (NAIC), which provided free access to databases, through reference specialists who collected HIV/AIDS-related resources for scientific researchers, service organizations, and the general public (CDC, 1990). Although NAIC paralleled a library's traditional role of developing and providing access to a collection of information resources, it was not a library managed by LIS professionals; rather, it was a service managed by medical, health care, and social welfare professionals. It was not until approximately half a 


\section{SLIS Student Research Journal}

July 2011, Volume 1, Issue 1

decade after the research of LIS professionals Self et al. (1989) that the United States' two major national libraries, the Library of Congress (LC) and the National Library of Medicine (NLM), articulated a policy for library collection development of HIV/AIDS information resources. To suggest that NAIC had no influence on LIS professionals would be inaccurate, as Detlefsen and Huber (1991) favorably mentioned free posters from NAIC used in AIDS education displays to LIS audiences.

Among perceptions about HIV/AIDS in the LIS community during the late 1980s and early 1990s, Detlefsen and Huber's (1991) case study succinctly described how the School of Library and Information Science (SLIS) at the University of Pittsburgh combatted negative stereotypes of HIV/AIDS by raising HIV/AIDS awareness in its courses. Detlefsen and Huber (1991) included an annotated bibliography of print materials about the social aspects of HIV/AIDS, and even though their study is now 20 years old, LIS professionals can still derive general collection practices from it. In particular, libraries can consider creating exhibits and bibliographical materials about HIV/AIDS and develop instructional materials usful to other academic disciplines.

Despite identifying children and young adults as a group in need of HIV/AIDS materials, Detlefsen and Huber (1991) failed to emphasize the importance of collecting HIV/AIDS materials that specifically addressed high risk groups of MSM and African Americans; instead, the authors asserted that "AIDS does not discriminate by race, creed, color, age, or sexual orientation" (p. 237). Combating prejudiced views of HIV/AIDS by recognizing the disease as a universal threat is, and has comonly been, a successful technique to winning widespread public support, but LIS professionals should not neglect to source and collect current data about HIV/AIDS, and synthesize it into relevant information that may assist those at higher risk from becoming infected.

Hofacket (1993), an outspoken champion of HIV/AIDS information resources collection development, posed questions and concerns relevant to public libraries to develop HIV/AIDS collections, and urged librarians to identify resources that could be accessible to as many users and in as many formats as possible. She advocated that librarians consider their user populations' literacy levels, whether English is their users' preferred language, and recommended that librarians avoid censorship based on any personal assumptions about their user populations. Hofacket (1993) suggested materials that would be best for small libraries and encouraged large libraries to contact the AIDS Library (Philadelphia) for collection development recommendations because LC and NLM had yet to publish their joint policy on collecting HIV/AIDS information resources to guide libraries with sizable holdings. 


\section{Andrews: Collection Development of HIV/AIDS Resources}

As a conceptual basis for collection development, Hofacket (1993) stated that LIS professionals "can preserve and impose [their] own values, beliefs, and vocabulary on others, or [they] can present the honest, inclusive, understandable information that people need to stay healthy and alive" (p. 66). Bolstering this conceptual foundation, Hofacket (1993) asserted that her annotated bibliography's "intended audiences include[d] teens, men, and women; straight, gay, lesbians, or bisexual persons; intravenous drug users; and those who practice sadomasochism, oral, anal, or conventional sex" (p. 66), essentially every group at risk for contracting HIV. Hofacket (1993) also acknowledged information resources for prison populations; a group with a higher rate of confirmed AIDS cases than that of the general United States population since 1991, and more than three times higher by the end of 2004 (Maruschak, 2006).

Unfortunately, and commonly found in articles on HIV/AIDS collection development, Hofacket's 1993 bibliography now lists outdated materials. The author had then proposed acquiring many videos and some Spanish-language resources, perhaps in anticipation of both the increasing Latino population and the expansion of library media resources in the United States. Recognizing HIV/AIDS-related materials suitable for the Latino community again illuminates the importance of providing information to higher risk and/or minority groups disproportionately affected by HIV/AIDS. Like Detlefsen and Huber (1991), the recommendations by Hofacket (1993) addressed collection development for specific groups such as children, women, and the deaf, yet her focus was materials, including video and serial formats, suitable for those most at risk MSM and African Americans.

\section{Library of Congress (LC) and National Library of Medicine (NLM) HIV/AIDS Collection Development}

In 1994, LC and NLM established their joint policy on collecting HIV/AIDS resources. Like Self et al. (1989), LC and NLM recognized the proliferation of HIV/AIDS information resources as both libraries acknowledged "simultaneous demand for information on the topic from the lay public and health professionals" (LC, 1994, para 2). The libraries' joint policy observed the rapid dissemination of HIV/AIDS information from scholarly research to popular reading materials was an "unusual situation" (LC, 1994, para 2), thereby justifying a collection development policy that specifically addressed HIV/AIDS as a medical and social issue.

Considering the growth of scholarly research regarding HIV/AIDS within the LIS community, it is doubtful that the overall high supply and demand of HIV/AIDS resources alone prompted the LC and NLM to establish the joint policy. The LIS professionals involved in the policy's development were likely 


\section{SLIS Student Research Journal}

July 2011, Volume 1, Issue 1

aware of the LIS community's increasing awareness about HIV/AIDS issues as described by Detlefsen and Huber (1991), or perhaps they were encouraged by the HIV/AIDS-related collection policies developed by fellow LIS professionals such as Hofacket (1993). As models for libraries, in terms of collecting and cataloging materials, LC and NLM could not reasonably afford to lag behind other LIS professionals who were establishing focused HIV/AIDS information resource collections, and this may have served as an underlying catalyst to the two libraries' collaboration on a collection development policy.

Despite the joint policy, much of its structure and practices reveal divergent approaches that LC and NLM would take in developing HIV/AIDS information resource collections. Depending on their library users, LIS professionals can glean specific suggestions from the policy for developing local HIV/AIDS information resource collections. If a library's audience is primarily health professionals, it should follow the guidelines specific to the NLM, which "attempts to assemble a comprehensive collection of the scholarly biomedical literature of AIDS/HIV" (LC, 1994, para 5). Libraries with a broader audience should more closely follow the LC guidelines, which attempt "to acquire materials in all media which contribute to a knowledge of the cultural, ethical, psychological, legal, religious, social, economic, historical, and political aspects of AIDS/HIV" (LC, 1994, para 9). Public and academic libraries using this joint policy as an aid in developing their own HIV/AIDS collection policies should focus on LC's emphasis on audiovisual materials, which may be a more digestible medium for the general public in understanding HIV/AIDS issues.

Where LC and NLM converge in their joint policy is through their application of a collection level schema and four HIV/AIDS literature categories, though both often collect in each category at different levels. The policy charts literature category sub-categories and the collecting level that NLM and LC have adopted for each sub-category (LC, 1994). While higher risk minority groups such as MSM and African Africans are not explicitly mentioned in the schema, materials about them would certainly fall in the sub-categories of "Epidemiology of AIDS and HIV," which refer to "discrete populations" and "high risk groups" (LC, 1994, "AIDS Collecting Levels"). Such sub-categories are undoubtedly helpful to identify these minority groups from a statistical perspective, yet neither identify what these minority groups may face in their unique situations, nor how to educate or assist them in coping with HIV/AIDS. Admittedly, LC and NLM collect vast numbers of materials, but if one policy can approach epidemiology with such granularity it could also address other categories with the same depth. Another unfortunate weakness of the policy is, even with online databases such as NAIC and the comprehensive coverage of information formats, it fails to address online materials that can augment HIV/AIDS collections (CDC, 1990). 


\section{Andrews: Collection Development of HIV/AIDS Resources}

Dancy and Dutcher (2007) reported "HIV/AIDS continues to disproportionately affect certain groups in this country such as African American and Hispanic populations and minority women and children" (p. 324), and paralleled such disparity with the digital divide. Described by Gorman (2001), "if you are poor, disabled, rural, young, very old, and/or a resident of the inner city, it is more than likely that your access to 'the information age' is limited or nonexistent" (p. 10); thus, the digital divide illustrates the inadequate access to current HIV/AIDS information resources among these groups, and contributes to limiting people's knowledge to make informed decisions that may help them prevent contracting and spreading HIV and developing AIDS. NLM compensated for some deficits in its joint policy with LC through its collaborative efforts with the National Institutes of Health (NIH) Office of AIDS Research. Together, the two organizations sponsored the 1993 NIH HIV/AIDS Information Conference, which served "to review the various HIV/AIDS information services, assess NIH's current efforts in providing information services, and identify additional needs" (Dancy \& Dutcher, 2007, p. 323). Since 1994, NLM has helped fund organizations, including libraries, seeking to improve their access to HIV/AIDS information resources, and has contributed to promoting electronic materials on the HIV/AIDS epidemic (Dancy \& Dutcher, 2007). Public libraries have used NLM's financial support to "[enhance] both their print and video collections and [to establish] a technology base" (Dancy \& Dutcher, 2007, p. 324), actions aligned with Hofacket's (1993) multi-format collection suggestions.

\section{HIV/AIDS Epidemic and Women}

LC and NLM crafted their policy according to the diversity of HIV/AIDS information formats rather than the diversity of user populations, and this created a void in scholarly literature that LIS professionals quickly sought to fill through their own research and policy suggestions. Among these professionals were Gillaspy and Huber (1996), whose research identified women as a particular group in need of HIV/AIDS information resources because in 1995 women and children represented "the fastest growing group of new AIDS patients in the United States" (p. 24). Gillaspy and Huber (1996) believed that the HIV/AIDS epidemic would continue to precipitate among women, observing that "HIV+ women seem likely to continue more rapid disease progression and mortality rates than HIV+ men" (p. 24).

The most recent CDC reports on HIV/AIDS, however, invalidate this forecast; AIDS diagnoses among women decreased between 2005-2008, while HIV diagnoses among women during the same years remained stable (CDC, 2010b). For men, AIDS diagnoses remained stable between 2005-2008, while HIV diagnoses during the same period increased (CDC, 2010b). These figures suggest 


\section{SLIS Student Research Journal}

July 2011, Volume 1, Issue 1

that contrary to the mid-1990s fears expressed by Gillaspy and Huber (1996), HIV/AIDS remains a disease that predominantly affects men. Furthermore, Gillaspy and Huber (1996) failed to refine their argument for developing womenoriented HIV/AIDS information collections by not incorporating racial and ethnic differences into their research and instead addressing only geographic and linguistic data. Nevertheless, if Gillaspy and Huber (1996) had addressed racial and ethnic differences they could have outlined the state of HIV/AIDS information resources for women in the higher-risk groups of African American and Latino communities.

Gillaspy and Huber (1996) researched a related issue evident during the mid1990s, which was women with HIV/AIDS were not receiving as much attention as other groups from health care professionals due to the "paucity of literature" (p. 24) about women with HIV/AIDS. Gillaspy and Huber's (1996) conclusion that "access to health care goes hand-in-hand with access to information" (p. 24) is one that LIS professionals should consider when assessing their library user groups and specific needs for adequate HIV/AIDS information resources. By studying the HIV/AIDS-related information needs for a particular user group, Gillaspy and Huber (1996) augmented LC and NLM's policy of collecting diverse formats, such as speciality journals, conferences, monographs, videotapes, and newsletters, and to include electronic resource collections-a format distinctly absent in the LC and NLM's 1994 joint policy. However, Gillaspy \& Huber (1996) warned libraries not to focus solely on electronic resources, describing such as lacking due to their "insufficient scope, lags in indexing, and human error" (p. 36), issues that persist today. Gillaspy and Huber (1996) characterised the civic role of LIS professonals to provide HIV/AIDS collections with "information forms the key resource for all professionals working in the epidemic; therefore, as professional managers and providers of information, librarians occupy a central role in the struggle against this disease, whomever and wherever it strikes" (p. 37), an enduring statement applicable to several topics today.

\section{HIV/AIDS Collection Development during the Past Decade}

Within the past decade other LIS professionals have continued Gillaspy and Huber's (1996) user-oriented HIV/AIDS collection development policies. Perry (2001) stresses the civic role of public libraries to provide free or inexpensive HIV/AIDS information to users, especially minorities and the poor, and artciluates the challenges that both censorship and Judeo-Christian values pose on libraries when providing access to such resources. In contrast to LIS professionals Detlefsen and Huber (1991) who suggested the need for HIV/AIDS information resources for youth, Perry (2001) describes highly vocal opinions of LIS professionals, community groups, and media pundits who each suggest that 


\section{Andrews: Collection Development of HIV/AIDS Resources}

sexually explicit information should be restricted, and filtered on public computer terminals accessing the Internet in order "to protect the nation's youth" (p. 121). Opposing this view, the ALA Intellectual Freedom Committee (2000) states "libraries are governmental institutions subject to the First Amendment, which forbids them from restricting information based on viewpoint or content discrimination" ("Problems"), and cannot reasonably filter or control access to certain content, suggesting that parents take responsibility for regulating their children's Internet usage. Perry (2001) characterized the ALA as "traumatized" and "under attack" in its struggle to ensure "unhindered access to information representing the broadest spectrum of opinions possible" (p. 121).

Gross, Goldsmith and Carruth (2008) suggest current HIV/AIDS awareness education focuses on the epidemic in developing countries, which "may be an unintended message for young people in the United States that their own health is not at risk" (p. 400). LIS professionals must be aware that HIV/AIDS is still an epidemic in the United States, and that they can better serve American youth by arming them with sufficient and current HIV/AIDS information resources that may help them prevent contracting the disease.

Perry (2001) summarizes the historical reaction of libraries toward HIV/AIDS as responsive in terms of collection development yet lacking in terms of information services; he concludes that a more proactive approach is necessary, recommending that public librarians cooperate with local organizations to develop HIV/AIDS information services. Perry (2001) accentuates the importance of choosing materials suitable to the local population citing literacy, language, and the explicitness of content as major considerations, but adds that collection budgets should allow for some technical biomedical materials that users with HIV/AIDS will demand. For materials and online resources about HIV/AIDS for children, Perry (2001) recommends a collaborative approach with community members when selecting resources in order to minimize controversy that can arise from data about sexual and drug-related issues relevant to HIV transmission. Involving community members in the collection development process would better assist LIS professionals in directly identifying their users' HIV/AIDSrelated needs, rather than attempting to extract these needs from bibliometrics. By addressing minorities in specific sections of his bibliography, including the higher-risk MSM and African American groups, Perry (2001) revived Hofacket's (1993) inclusive collection development stance, which emphasized the needs of those most vulnerable in the HIV/AIDS epidemic that should underpin collection development decisions.

Williams (2007) exemplifies the collaborative model in her annotated bibliography, which has been a valuable resource for libraries that serve large African American populations, and is one of the few current bibliographies on 


\section{SLIS Student Research Journal}

July 2011, Volume 1, Issue 1

HIV/AIDS resources specific to this demographic. African Americans, as a higher risk group in the HIV/AIDS epidemic, deserve the focused attention of LIS professionals developing resource collections; figures cited by Williams (2007) strongly support such: "while they make up only 13 percent of the U.S. population, blacks accounted for a shocking 50 percent of Americans diagnosed with HIV/AIDS in 2004" (para 2). Criticizing the "sorry lack of print materials" (Williams, 2007, para 7) on HIV/AIDS and African Americans, she also references Hofacket (1993) as one of the last LIS professionals to adequately address the collection issue.

To develop collections of current materials, of various formats and for different audiences, Williams (2007) recommends a comprehensive set of resources pertinent to HIV/AIDS in the African American community, and an extensive list of relevant websites. Libraries that serve African American populations could benefit from adding the suggested materials to their collections and providing links to the online resources on their websites. One major recommendation of Williams (2007) is that librarians discard outdated medical books and only carry current literature because research findings and medical practices in the field of HIV/AIDS are rapidly changing. She also identifies the intersection of MSM and African Americans with title recommendations about the "down low" phenomenon and about gay African Americans. About the book, On the Down Low: A Journey into the Lives of "Straight" Black Men Who Sleep with Men, Williams (2007) urges "public library patrons will want this controversial title" ("For Individuals"), reiterating the demand of HIV/AIDS information described by Self et al. (1989) and the controversy of HIV/AIDS resources detailed by Perry (2001).

The HIV/AIDS Resource Library of the Columbus AIDS Task Force (CATF) in Columbus, Ohio is one library aligned with user-based collection development models and promoted in both Perry (2001) and Williams (2007). The HIV/AIDS Resource Library not only boasts a collection of interdisciplinary materials in diverse formats, it also "includes HIV resources of special interest to AfricanAmerican, GLBT, Hispanic, Native American, deaf, adolescent, and over-50 communities" (Deevey \& Behring, 2005, p. 30), therefore acknowledging that the HIV/AIDS epidemic affects different communities in different ways. This library reflects NLM's efforts to establish HIV/AIDS information resource collections for diverse populations, (Deevey \& Behring, 2005).

In considering how libraries can organize HIV/AIDS collections, Deevey and Behring (2005) reviewed the ten domains concept described in Huber and Gillaspy's 1996 work, HIV/AIDS and HIV/AIDS-Related Terminology, and concluded it does not adequately correspond with reference questions typically asked by library users. In fact, Deevey and Behring (2005) identified the 
Andrews: Collection Development of HIV/AIDS Resources

cataloging of HIV/AIDS collections as an issue that must continue to evolve, stating, "libraries may need to consider organizing HIV materials by cultural groups in order to improve information services to specific populations" (p. 35), an approach that could help disseminate HIV/AIDS information to higher risk groups such as African Americans and MSM.

\section{A New Approach to Collection Development}

Fortunately during the past decade, researchers of HIV/AIDS-related collection development have focused on higher risk groups and on innovative strategies to address specific collection voids. Ondrusek (2002) describes an outstanding array of potential collection management methods for public and academic libraries whereby HIV/AIDS resources can be used for non-specialist research, emphasizing a development plan based on a chronological timeline of HIV/AIDS discoveries and publications. Ondrusek (2002) argues for the use of her timeline approach for three reasons: HIV/AIDS information has an interdisciplinary influence; HIV/AIDS events change quickly; and readers need accurate materials. Applying the Ondrusek (2002) timeline librarians can determine which materials to discard

Ondrusek's (2002) recommendations are rigorous: she advocates an annual evaluation of HIV/AIDS materials as well as incorporating HIV/AIDS reference replacements in the annual acquisitions budget due to the rapid changes in HIV/AIDS research and health care. She does, however, point out the value of retaining materials with retrospective information, which could be moved to a special collection or a closed reference section (Ondrusek, 2002). Additionally, Ondrusek staunchly supports supplementing or replacing library print collections with electronic versions and online resources because online materials can be revised quickly to reflect the most up-to-date information. LIS researchers Robinson and Graham (2010) caution that "even in higher income countries, such as the United States, nearly half the population has limited health literacy skills" (p. 295); therefore, LIS professionals need to act prudently about highly technical electronic resources and guide users in fully understanding the information. They suggest LIS professionals offer information literacy classes to low-income HIVpositive patrons so this group can learn "what Internet health resources exist, where to find them on the Internet, how to evaluate what they find, and how to incorporate the new information into their existing knowledge base" (Robinson and Graham, 2010, p. 301).

Ondrusek's (2002) research of HIV/AIDS-related materials is primarily focused on global audiences as she contends "heterosexual sex was (and is) the main route of HIV transmission throughout Africa" (p. 50). Sub-Saharan Africans are a higher risk group than Americans to contract HIV, and of an "estimated 34.3 


\section{SLIS Student Research Journal}

July 2011, Volume 1, Issue 1

million adults and children living with HIV, worldwide, about 22.5 million are Africans scattered throughout sub-Saharan countries - many untreated and many more still undiagnosed" (Ondrusek, 2002, p. 64). While Ondrusek's research is not specific to higher risk groups such as MSM and African Americans, LIS professionals can still consider how its intersections and global discourse can help improve HIV/AIDS information resource collections in American libraries.

\section{Conclusion}

Since the late 1980s under the auspice of the ALA, LIS professionals have recognized the importance of ensuring equal access of information resources to their users affected by the HIV/AIDS epidemic; however, those who pioneered the development of HIV/AIDS information resource collections gravitated toward policies for broad audiences and not higher-risk groups including MSM and African Americans. Fortunately, Hofacket (1993) diverged from this 1990s trend, and LIS professionals subsequently researching HIV/AIDS-related collection development during the past decade have echoed her recommendations for both diverse formats and coverage to multiple user groups. Among the recommendations of Perry (2001) and Williams (2007) are an emphasis on establishing electronic resource collections, refining cataloging practices, and improving users' information literacy skills to make online resources more accessible and understood.

Although current research into HIV/AIDS-related collection development is oriented more toward Africa and developing countries, LIS professionals must not overlook the reality that HIV/AIDS remains an incurable epidemic in the United States. Americans, specifically MSM and African Americans, still desperately need access to current, understandable materials about HIV/AIDS, whether it's to answer specific medical questions and concerns, to prevent HIV infection, or to remain healthy as possible living with HIV/AIDS. MSM and African American have been most vulnerable to the disease, and their HIV/AIDS rates of infection are unfortunately not dropping. Rather than overlook MSM and African Americans, LIS professionals should advance these groups' information needs and promote collections and services that contribute significant, beneficial information resources that may help reverse the disproportionate risks of contracting HIV/AIDS among the MSM and African American communities. 
Andrews: Collection Development of HIV/AIDS Resources

\section{References}

American Library Association. (1988). Resolution on access to the use of libraries and information by individuals with physical or mental impairment. Retrieved from http://www.ala.org/ala/aboutala/offices/oif/statementspols/ifresolutions/res olutionimpairment.pdf

American Library Association. (2009). Services to persons with disabilities: An interpretation of the Library Bill of Rights. Retrieved from http://www.ala.org/ala/issuesadvocacy/intfreedom/librarybill/interpretatio ns/Services $\% 20$ to\%20Persons\%20.pdf

American Library Association Intellectual Freedom Committee. (2000).

Statement on library use of filtering software. Retrieved from http://www.ala.org/ala/aboutala/offices/oif/statementspols/ifresolutions/sta tementlibrary.cfm

Americans with Disabilities Act. (1996). Questions and answers: The Americans with Disabilities Act and persons with HIV/AIDS. Retrieved from http://www.ada.gov/pubs/hivqanda.txt

Americans with Disabilities Act. (2011). Americans with Disabilities Act of 1990, as amended (2008). Retrieved from http://www.ada.gov/pubs/adastatute08.htm

Centers for Disease Control and Prevention. (1990, October, 5). Notices to readers National AIDS Information Clearing House. Morbidity and Mortality Weekly Report, 39(39), 697-698. Retrieved from http://www.cdc.gov/mmwr/preview/mmwrhtml/00001789.htm

Centers for Disease Control and Prevention . (2010a). Basic information about HIV and AIDS. [Home page]. Retrieved from http://www.cdc.gov/hiv/topics/basic/index.htm 


\section{SLIS Student Research Journal}

July 2011, Volume 1, Issue 1

Centers for Disease Control and Prevention . (2010b). HIV Surveillance

Report: Diagnoses of HIV infection and AIDS in the United States and dependent areas, 2008. (vol. 20). Retrieved from

http://www.cdc.gov/hiv/surveillance/resources/reports/2008report/pdf/200

8SurveillanceReport.pdf

Dancy, N., \& Dutcher, G. (2007). HIV/AIDS information outreach: A community-based approach. Journal of the Medical Library Association, 95(3), 323-329. doi:10.3163/1536-5050.95.3.323

Deevey, S., \& Behring, M. (2005). HIV/AIDS reference questions in an AIDS service organization special library. Medical Reference Services Quarterly, 24(3), 29-37. doi:10.1300/J115v24n03_03

Detlefsen, E., \& Huber, J. (1991). AIDS awareness in the LIS classroom and school. Journal of Education for Library and Information Science, $32(3 / 4), 237-239$.

Gillaspy, M., \& Huber, J. (1996). The literature of women and the acquired immunodeficiency syndrome (AIDS): Implications for collection development and information retrieval. Medical Reference Services Quarterly, 15(4), 21-39. doi:10.1300/J115V15N04_03

Gorman, M. (2001). Human values in a technological age. Information Technology and Libraries, 20(1), 4-11.

Gross, M., Goldsmith, A., \& Carruth, D. (2008). What do young adult novels say about HIV/AIDS? A second look. Library Quarterly, 78(4), 397-418. doi:10.1086/591181

Hofacket, J. (1993). Intensive care: Materials on AIDS and HIV. Library Journal, 118(1), 65-68.

Library of Congress. (1994). Acquired immunodeficiency syndrome (AIDS) and the human immunodeficiency virus (HIV) (Joint policy with NLM). Cataloguing and Acquisitions. Collection Development, Policies. 
Andrews: Collection Development of HIV/AIDS Resources

[Archived Home page]. Retrieved from

http://web.archive.org/web/20100610105621/http://www.loc.gov/acq/dev pol/aids.html

Maruschak, L.M. (2006, November). HIV in prisons, 2004. Bureau of Justice Statistics. Bulletin, NCJ 213897, 1-12. Retrieved from http://bjs.ojp.usdoj.gov/content/pub/pdf/hivp04.pdf

Ondrusek, A. (2002). Evaluating an HIV/AIDS book collection using a timeline approach. Collection Management, 26(1), 47-75. doi:10.1300/J105v26n01_04

Perry, G. (2001). HIV/AIDS information in public libraries: A "common ground" approach to service delivery and focus on select resources. Public Library Quarterly, 18(3/4), 119-137. doi:10.1300/J118v18n03_14

Robinson, C. , \& Graham, J. (2010). Perceived Internet health literacy of HIVpositive people through the provision of a computer and Internet health education intervention. Health Information and Libraries Journal, 27(4), 295-303. doi:10.1111/j.1471-1842.2010.00898.x

Self, P., Filardo, T., \& Lancaster, F. (1989). Acquired immunodeficiency syndrome (AIDS) and the epidemic growth of its literature. Scientometrics, 17(1-2), 49-60. doi:10.1007/BF02017722

Williams, E. (2007, January 15). Collection development "African-Americans and AIDS": Sounding a silent epidemic. Library Journal. Retrieved from http://www.libraryjournal.com/article/CA6403624.html 